\title{
Desafios da práxis freireana em tempos de pandemia: ensino remoto e gestão educacional no proeja
}

\section{Challenges of freirean's practices in pandemic times: remote education and school management in PROEJA Retos de las práticas freireanas en tiempos de pandemia: ense-nanza a distancia y gestión educativa en PROEJA}

EDNA CASTRO DE OLIVEIRA

https://orcid.org/0000-0003-0798-7090

Universidade Federal do Espirito Santo

Programa de Pós-graduação em Educação

Linha de Pesquisa de Educação, Formação Humana e Políticas Públicas

Espírito Santo, ES, Brasil

ALDO REZENDE

https://orcid.org/0000-0001-7239-1002 Instituto Federal de Educação, Ciência e Tecnológica do Espirito Santo Programa de Mestrado em Educação Profissional e Tecnológica Linha de Pesquisa em turismo, subárea de geografia urbana, regional e cultural Espírito Santo, ES, Brasil

MARIA JOSÉ DE RESENDE FERREIRA https://orcid.org/0000-0001-9442-0468 Instituto Federal de Educação, Ciência e Tecnológica do Espirito Santo

Programa de Pós-graduação em Educação Linha de Pesquisa de Estudos em Educação e Inovação

Espírito Santo, ES, Brasi

PATRÍCIA HELMER FALCÃO

https://orcid.org/0000-0003-4325-5591

Universidade Federal do Espírito Santo

Programa de Mestrado Profissional em Educação Profissional e Tecnológica

Departamento de Educação Vitória, ES, Brasi

\begin{abstract}
Resumo: Como estudo em andamento, o texto revisita o pensamento e práxis de Paulo Freire em suas relações com o momento presente para pensar os desafios da gestão educacional, na adoção do ensino remoto no Proeja, em função da Covid-19. Os pressupostos da pesquisa documental e da sistematização de experiência foram estratégias de investigação articuladas, que permitiram desvelar os movimentos dialógicos e participativos dos sujeitos como fundantes na definição de ações para a redução dos impactos do ensino remoto junto a estudantes do Curso Técnico Integrado em Hospedagem do Proeja.
\end{abstract}

Palavras-chave: Pensamento freireano; Proeja; Ensino remoto; Diálogo; Gestão Democrática 


\begin{abstract}
As an ongoing study, the text revisits the thought and praxis of Paulo Freire, in their relation to the present moment, in order to think about the challenges of educational management, when faced with the adoption of remote education in Proeja, due to Covid-19. The assump-tions of documentary research and the systematization of experience were articulated inves-tigation strategies, that allowed to unveil the dialogical and participatory movements of the subjects, as the key factors in the definition of actions to reduce the impacts of remote edu-cation on students attending Proeja's Professional Technical High School in Hosting.
\end{abstract}

Keywords: Freirean thought; Proeja; Remote teaching; Dialogue; Democratic management

Resumen: Como estudio en curso, el texto revisa el pensamiento y la praxis de Paulo Freire, en sus relaciones con el momento presente, para reflexionar sobre los desafios de la gestión educativa, desde la adopción de la educación a distancia en Proeja, debido al Covid 19. Los supuestos de la investigación documental y la sistematización de la experiencia fueron estrategias de investigación articuladas, que permitieron develar los movimientos dialógicos y participativos de los sujetos, como fundamento en la definición de acciones para reducir los impactos de la educación remota con estudiantes del Curso Técnico Integrado en Hosting de Diseño.

Palabras clave: Pensamiento freireano; Proeja; Enseñanza remota; Diálogo; Gestión democrática.

\title{
INTRODUÇÃO
}

Desde os seus primeiros escritos, que emergem das experiências vividas junto a homens e mulheres do povo, Paulo Freire revela seu envolvimento com a defesa insistente da superação dos grandes problemas nacionais, que só poderiam ser equacionados a partir de uma relação orgânica com a "nossa contextura histórico-cultural" (FREIRE, 2001a. p. 9). Dentre suas preocupações o problema educacional ocupava destaque ao considerar que no contexto de uma sociedade em transição, como a brasileira, o planejamento educacional precisava responder aos valores que se impunham, requerendo da educação uma relação de organicidade e integração com as questões do seu tempo.

Nas suas reflexões sobre o Brasil como uma sociedade em transição, Freire se debruçava sobre a experimentação da abertura que se fazia para um novo clima cultural e sua tendência para a democratização cultural e política. Ao mesmo tempo, alertava para os riscos do recuo por parte de forças contrárias, “irracionalmente sectárias ameaçadas nos seus privilégios" (FREIRE, 1967, p.82), em função da rachadura da sociedade brasileira. Uma sociedade fechada "reflexa na sua economia. Reflexa na sua cultura. Por isso alienada. Objeto e não sujeito de si mesma. Sem povo" (p.48). 
Essas foram as condições que, segundo ele, viabilizaram a emergência do povo do silenciamento em que até então estivera submerso, na sua inexperiência democrática, para suas primeiras experiências de participação. Sua práxis problematizadora das várias práticas sociais demandava a afirmação da democratização fundamental, que reiterava a importância da participação da sociedade nos rumos do país e de sua educação, a qual haveria de se fazer pela democratização da cultura.

Envolvido por esse clima e nessas condições, Freire, como educador, passou a se inserir, juntamente com outros intelectuais, em busca de caminhos que pudessem ajudar o país no seu processo de desenvolvimento, por meio do qual a sociedade brasileira passasse a se assumir como sociedade sujeito, voltada para o conhecimento e a compreensão de seus problemas. Nesse movimento, ele viu na educação, uma das possibilidades de auxiliar o processo de emersão do povo brasileiro.

A conjuntura exigia, segundo ele, uma educação que fosse corajosa para tratar os problemas nacionais como os alarmantes índices de analfabetismo e sua superação. Entretanto, tinha ciência de que isso não poderia ser feito pelo veio de uma alfabetização puramente mecânica. Para esse educador, "O problema [...] prosseguia e transcendia a superação do analfabetismo e se situava na necessidade de superarmos também a nossa inexperiência democrática” (FREIRE, 1967, p.94). Assim, defendia a necessidade de uma educação que se colocasse criticamente, desenvolvendo junto ao povo, e com ele, sua capacidade de apropriação de leitura dos temas da atualidade brasileira numa "posição de tomada de consciência, na emersão que fizera no processo de nossa realidade" (p.103).

Imbuído desta convicção, Freire lançou mão das experiências desenvolvidas no âmbito do Serviço Social da Indústria (Sesi) e também com a educação de adultos, junto aos grupos de educação popular, a partir das quais demarcou, com sua práxis, a ênfase de uma "alfabetização direta e realmente ligada à democratização da cultura" (p.104), em que aprendizes se assumissem como sujeitos.

Desde então, afirmou-se a opção de Freire por uma educação que promovesse a transitividade da consciência do povo na apreensão dos problemas sociais, tornando-se permeável a esses problemas. Por uma educação criticizadora, capaz de "colaborar com o [povo] na indispensável organização reflexiva de seu pensamento. Educação que lhe pusesse à disposição meios com os quais fosse capaz de superar a captação mágica ou ingênua de sua realidade, por uma dominantemente crítica" (p.106). 
A retomada de algumas categorias que marcam os escritos iniciais de Freire -democratização fundamental, democratização da cultura e inexperiência democrática - a partir de suas fontes originais, como Karl Mannheim (18931947), por exemplo, nos chama a refletir sobre as condições atuais da sociedade brasileira, neste momento dramático do contexto político nacional, de crise econômica, política, ambiental e moral, agravada pela pandemia do Coronavírus SarsCoV-2 (Covid-19).

Esse contexto leva-nos a confrontar a atualidade das ideias de Freire quanto aos sentidos da fase de trânsito, que experimentava a nossa sociedade a partir das transformações mundiais do pós-segunda guerra, do surto da industrialização e da efervescência cultural e política que tomava conta do país, a qual se evidenciava com força nos movimentos de cultura popular do Recife. O trânsito se impunha como um "elo entre uma época que se esvaziava e uma nova que ia se consubstanciando, tinha algo de alongamento e algo de adentramento. De alongamento da velha sociedade que se esvaziava [em seus valores] e que despejava nele querendo preservar-se" (FREIRE, 1967, p. 47), à vista de novos valores e temas que emergiam. A tendência do trânsito, na análise desse educador, era a de abertura para a democratização da sociedade. No entanto, explicita que essa abertura se dava

pelo jogo das contradições bem fortes de que se nutria, ser palco da superação dos velhos temas e da nova percepção de muitos deles. Isto não significava, contudo, que neste embate entre os velhos e os novos temas ou a sua nova visão, a vitória destes e destas se fizesse facilmente e sem sacrifícios (FREIRE, 1967, p.47).

Nesse período, demandava, assim, a luta, e, portanto, a necessidade de manter a disposição de seguir no trabalho com o povo pelo veio da educação, mesmo a despeito das forças conservadoras que buscavam impedir a emergência das massas. Isso caracterizava, de acordo com Freire, uma antinomia fundamental, expressa atualmente pela polarização. De um lado, a "inexperiência democrática" forjada no âmbito do processo de colonização e, de outro, a "emersão do povo na vida pública nacional, provocada pela industrialização do país” (FREIRE, 2001a, p. 26).

O fenômeno da emersão é marcado, assim, por posturas que expressam a inexperiência democrática, pelo veio do poder policial que se impõe no “desrespeito aos direitos dos mais fracos [...], 'inexperiência' que explica a prática reveladora do clã consubstanciada na fórmula 'aos amigos tudo, [...] aos inimigos a lei"'(FREIRE, 2001a, p.26). Posturas que procuravam a submissão incondicional do povo às autoridades, mesmo sob pressão, e que reafirmavam 
a ausência de disposições do "sentimento do Estado Nacional [...] base para repousar a democracia verdadeira e a consciência da coisa pública de interesse comum" (p.27).

As experiências gestadas naquele cenário, no trato com questões sociais mais amplas de inexperiência democrática, pautadas por Freire, são inspiradoras para a leitura do momento presente, que está a nos exigir discernimento na captação dos temas que confrontam a nossa frágil democracia frente aos significativos recuos sob a égide do atual governo de caráter fascista.

As elites que seguem comandando o país, ao se sentirem ameaçadas em seus privilégios, temem também, como antes, a participação do povo nas ruas, mesmo restrita pela crise sanitária. Num contexto que tem desencadeado a destruição das conquistas democráticas, utilizam-se da mesma lógica do autoritarismo e da tentativa de silenciamento e de repressão aos que se levantam contra o regime, incluindo aí a perseguição e a demonização do pensamento e da práxis de Freire, sob as mesmas acusações, de ameaças do comunismo, desferidas pelo golpe de1964 (FREIRE, 1967). Desde então, o país experimenta retrocessos que tendem a submergir a população mais pobre em condições subumanas de vida, ao serem atacadas as conquistas do povo brasileiro no campo dos direitos sociais e trabalhistas.

Assim, de forma atualizada, testemunhamos, no momento presente, tensões e contradições semelhantes às vividas pela sociedade em transição, pautada por Freire, na qual se originaram os seus escritos e com a qual se envolveu no século passado. Não obstante os riscos dos recuos, procurou responder aos desafios do seu tempo pela mediação da educação.

A tendência de um movimento de democratização fundamental, evidenciada naquele contexto pela emergência das massas, é também ameaçada de recuo por forças contrárias à participação dessas, de forma soberana, no desenvolvimento econômico, em relação ao domínio e à condução dos destinos da nação. De forma análoga, mas também distinta, vivemos no presente vários recuos protagonizados pelos donos do poder ao fazerem reemergir "um projeto de país francamente predatório, por parte das elites locais que não se encontram apenas cada vez mais associadas a grupos estrangeiros, mas também cada vez menos identificadas com a população nacional” (MIGUEL, 2019, p.13-14). Recuo que se aprofunda ainda mais pela "crescente desnacionalização da economia e abandono de qualquer pretensão de afirmação da soberania nacional" (p. 12).

Somos, assim, confrontados, desde o golpe jurídico parlamentar de 2016, que desemboca na eleição de 2018, com o acirramento do fenômeno da "desdemocratização", caracterizado como um processo em seu pleno curso, cuja cena política configura-se de modo "a tornar inefetivo qualquer comportamento 
democrático, e tornar efetivos apenas os comportamentos antidemocráticos" (DIAS, 2020, p.8). Esse fenômeno tem intensificado, tal qual anunciada por Freire (1967, p. 21), "a ameaça dos irracionalismos à nossa destinação democrática", considerando ainda, como ele afirmava, "a democracia e a liberdade como possibilidades históricas".

Os ataques à grande massa da população mais pobre e vulnerável e o distanciamento cada vez maior do povo nas decisões de interesse do bem-estar comum, e de modo específico, os ataques e ameaças de destruição da educação pública remete-nos mais uma vez a Freire, quando afirma a impossibilidade de democracia sem povo, e mesmo quanto ao que ele nos alerta frente às ameaças à autêntica democracia. O desafio é seguirmos como educadoras(es) com a tarefa da educação crítica, "educação dialogal e ativa, voltada para a responsabilidade social e política, "caracterizada" pela profundidade na interpretação dos problemas" (FREIRE, 1967, p.60).

A partir dessas reflexões, situamos a relevância da temática em estudo e suas conexões com o contexto global, em tempo de ameaças e desqualificação da coisa pública, de exacerbada defesa dos interesses privados das elites, que seguem afirmando a todo custo, a hegemonia do mercado e a distorção de toda e qualquer iniciativa que objetiva a construção de uma sociedade mais justa, como uma "sociedade para si" (FREIRE, 1967). Com este horizonte, insistimos em reafirmar a tese freireana da democratização da cultura, que toma a educação como uma das ferramentas para o trabalho de "transformação do mundo com vistas à superação das injustiças sociais” (FREIRE, 2013, p.181).

O texto está organizado em três partes, além desta introdução e das considerações finais. $\mathrm{Na}$ primeira parte, revisitamos as experiências de gestão da educação, desenvolvidas por Freire no Brasil, em momentos distintos, o que abre para reflexões sobre o início de suas primeiras experiências de gestão no Sesi, no Movimento de Cultura Popular (MCP) e como gestor municipal em São Paulo. Na sequência, trazemos as contradições das práticas da gestão educacional que sutilmente têm fortalecido as estruturas burocráticas de controle da escola, enquanto território político em permanente disputa. Na última parte, por meio dos pressupostos e das orientações da pesquisa documental e da metodologia da sistematização da experiência, desvelamos o movimento de resistência à adoção do ensino remoto pautado pela proposta de atividades pedagógicas não presenciais - APNPs, e pela adesão às atividades complementares de ensino - ACE, nas turmas do Curso Técnico Integrado em Hospedagem do Programa Nacional de Integração da Educação Profissional com a Educação Básica na Modalidade de Educação de Jovens e Adultos (Proeja) do Instituto Federal do Espírito Santo (Ifes) campus Vitória. 


\section{FREIRE E SEUS PERCURSOS EM EXPERIÊNCIAS DE GESTÃO EDUCACIONAL NO BRASIL}

Como vimos, desde as primeiras inserções de Freire na vida nacional, suas preocupações voltaram-se para um fazer educativo, capaz de envolver o povo no estudo e no debate dos problemas da sociedade brasileira, que afetavam a vida de milhares de pessoas e impediam o desenvolvimento da nação.

Sua preocupação com os deficits da educação no país, em meados do século passado, (FREIRE, 1967), com o número de crianças fora da escola e com o analfabetismo, que atingia 16 milhões de pessoas de 14 anos de idade ou mais, é atualizada e acrescida quando remete-se “à luta [...] contra os alarmantes índices de reprovação de nossas escolas, fenômeno que a ingenuidade ou a malícia de muitas(os) educadoras(es) chamam de evasão escolar" (FREIRE, 2013, p. 146).

Embora se tenha avançado na ampliação da oferta da educação pública, no século XXI, persiste ainda um número alarmante de pessoas na condição de analfabetismo - são 11 milhões de pessoas com 15 anos ou mais. Nesse grupo, a taxa de analfabetismo aumenta conforme os grupos de idade, no qual pessoas com 15 anos ou mais correspondem a 6,6\% do número de analfabetos; 25 anos ou mais, 7,9\%; 40 anos ou mais, 11,1\%; e 60 anos ou mais, 18\% (PNAD, 2019). Dentre esses estão os sujeitos da Educação de Jovens e Adultos (EJA) inseridos no Proeja.

As críticas de Freire à organização da escola primária no Brasil, em meados do século XX, já destacavam "o descaso dos poderes públicos, sobretudo federais" com os gastos por uma escola capaz de cumprir a sua tarefa de "dar educação básica ou fundamental ao povo brasileiro" (FREIRE, 2001a, p.88). Uma escola cuja gestão da educação fosse marcada pelos princípios, então defendidos, de abertura à participação democrática da comunidade escolar nas decisões, em sintonia com o clima de democratização fundamental da sociedade.

É possível situar na defesa de sua tese de livre docência na Universidade do Recife, em 1959, a incorporação de certas práticas de gestão participativa levadas a efeito quando de sua atuação, por uma década, no Sesi, ao assumir a Direção da Divisão de Educação e Cultura e depois sua direção geral. Num contexto em que era demodê falar de "co-gestão", segundo Paulo Rosas (2001, p. LX), Freire iniciou nesse espaço

a vivência de administrar com, ultrapassando o para, cujo conteúdo se associava a uma atitude benevolente do doador. [Ele] desenvolveu no Sesi uma inovadora prática de administração participativa, somente superada nos anos 50, pela também inovadora ação do engenheiro Pelópidas Silveira na prefeitura de Recife. 
Embora atuando numa organização de caráter assistencialista e patronal, essa experiência de gestão acabou por fundamentar as bases do pensamento de Freire. Ao refletir sobre as práticas aí desenvolvidas, considerava que seria "ingênuo pensar que o Sesi fosse expressão da bondade incontida da classe dominante, que tocada pelas necessidades de seus trabalhadores, o criaria para ajudá-los" (FREIRE, 2013, p. 135)

Freire empenhou-se, assim, em exercitar o que defendia como possibilidade de democratização da cultura pelo veio da educação. Uma proposta educacional integrada à sua realidade, com uma escola que se abrisse democraticamente à participação e que se voltasse para compreensão dos problemas de seu entorno e do país.

Tomando como referência os estudos que situam as experiências de gestão da educação, vividas por Freire, embora não seja o intuito de aqui reproduzilas, intentamos, no cotejamento desses estudos, com destaques para as conexões de suas experiências e a coerência com que o nosso mestre seguiu defendendo: manifestar a possibilidade de se fazer uma outra educação, no empenho da construção de uma escola democrática, aberta à participação do povo.Essa escola defendida por Freire, configura a gênese de seu pensamento pedagógico e de sua proposta de educação libertadora. A experiência vivenciada na gestão da educação dentro de uma instância patronal, que se afirmava como assistencialista, fez com que se aclarassem para Freire suas convicções acerca da escola democrática. Uma escola que estimulasse a "curiosidade crítica dos educandos, uma escola que, sendo superada, fosse substituída por outra em que já não se apelasse para a memorização mecânica dos conteúdos [...], mas em que ensinar e aprender fossem partes inseparáveis do mesmo processo: o de conhecer" (FREIRE, 2013, p.143).

Com essa mesma intencionalidade, empenhou-se na co-gestão administrativa, exercitando, nas primeiras experiências, com suas equipes ainda no Sesi, uma gestão democrática que possibilitasse abertura "tanto quanto possível [...] à ingerência dos operários e suas famílias em diferentes níveis [nas decisões, como aprendizagem de participação na] democracia pela experiência da crítica, da denúncia, do anúncio" (FREIRE, 2013, p.144). Ao refletir sobre essa prática, Freire destacou a importância dos espaços criados para o exercício do diálogo, da escuta, da participação da comunidade, "do direito à voz das classes populares" (p.139). Para Freire (2001a, p.23), na realização dos projetos 
o caminho foi sempre o do diálogo, através de que ia se conhecendo progressivamente a realidade. Realidade em análise, em discussão, posta em evidência, nunca previamente estabelecida por nós, [...]. E dessas discussões verdadeiramente democráticas, entre nós e os líderes operários [em assembleias] muitas vezes saímos vencidos.

As experiências iniciais de gestão foram incorporadas mais tarde no trabalho com o Movimento de Cultura Popular (MCP), criado por Miguel Arraes, por meio do qual desenvolveu, nas zonas populares de Recife, seu trabalho de alfabetização de adultos com os Círculos de Cultura. Para Freire (2013, p.176), o MCP tinha uma "compreensão crítica do papel da cultura no processo de formação, como no da luta política pelas necessárias mudanças de que a sociedade brasileira precisava e continua a precisar".

Essas experiências se desdobraram em outras ações quando assumiu o trabalho de Gestão como Diretor do Serviço de Extensão Cultural da Universidade do Recife. Do envolvimento neste trabalho temos sua experiência de alfabetização conhecida mundialmente, como as 40 horas de Angicos-Rio Grande do Norte. A partir daí, como sabemos, foi convidado pelo então ministro Paulo de Tarso para coordenar o Plano Nacional de Alfabetização.

Após 15 anos de exílio, destaca-se outra experiência de gestão de Freire, como Secretário Municipal de Educação da cidade de São Paulo (1989-1991), no mandato de Luiza Erundina. Freire (2013, p.191), em seu compromisso com "a luta democrática pelo sonho possível de uma sociedade mais justa", e em face do contexto e das condições de infraestrutura da rede municipal, explicitadas por ele em seus escritos $(1991 ; 2001 b)$, retomou, de certa forma, suas ideias e experiências interrompidas, para exercitar o trabalho de gestão democrática em São Paulo. Passou a reafirmar, com força, a bandeira da escola democrática, defendendo o projeto de uma escola pública popular.

As aprendizagens de gestão democrática em que se exercitara em seu percurso de vida foram mobilizadas num contexto extremamente desafiador. Para intervir sem impor, Freire (1991) envolveu a participação democrática das unidades escolares e suas comunidades, na tarefa de mudar as práticas de gestão autoritárias, ao mesmo tempo em que sonhava em "mudar a cara da escola" (p.47).

Nessa práxis de escuta e diálogo com as comunidades, reafirmou a concepção de gestão democrática como condição para a melhoria da qualidade do ensino (FREIRE, 1991). Para ele, "é a gestão democrática que gera a escola de qualidade social” (CAETANO; ARELARO, 2020, p.12). A formação permanente das(os) docentes assumiu um lugar singular na construção do projeto pedagógico como espaço de superação de equívocos que se faziam obstáculos à prática em processo (FREIRE, 1991). 
Nas interlocuções e conexões entre as experiências e desafios da práxis freireana de gestão da educação e os que são lançados à prática educativa na atual crise pandêmica, algumas indagações se levantam. Quando situamos a questão política, tão enfatizada por Freire, temos chaves de leituras para compreender as relações implicadas nas decisões relativas aos estudantes do Proeja, envolvidos nesta pesquisa: "[...] Tem que ver com quem decide sobre que conteúdos ensinar, que participação têm os estudantes, [...] os professores, os movimentos populares na discussão em torno dos conteúdos programáticos" (FREIRE, 1991, p.44-45). As marcas da inexperiência democrática e do autoritarismo tendem a se confrontar com a compreensão crítica dos seus problemas, que (as)os estudantes passam a ter, bem como das condições de trabalho, de educação e vida nesse período de pandemia.

\section{CONSIDERAÇÕES SOBRE GESTÃO EDUCACIONAL NO CONTEXTO DA PANDEMIA}

É notório, na atualidade, o intencional movimento de precarização e despolitização da educação escolar pública, além da crescente onda de avanço dos fundamentalismos políticos e religiosos, circunscritos à propalada negação dos pressupostos científicos, assim como do ascendente movimento de desqualificação do papel das(dos) intelectuais, em especial da(os) educadoras(es).

O desafio de pensar a educação pública nos impulsiona quando se constatam, no âmbito da gestão educacional, as flagrantes condutas de profissionais da educação que expressam a autoridade assentada em bases autoritárias de exercício do poder. Atitudes sutis que comprimem e comprometem as possibilidades de diálogos e as próprias relações interpessoais do direito à liberdade de expressão e do pensamento. São condutas que, indiscutivelmente, esvaziam os sentidos e significados da horizontalidade possível no campo do diálogo e das decisões, haja vista que "se não há liberdade sem autoridade, não há também esta sem aquela” (FREIRE, 1987, p. 103).

Assim, na área da gestão educacional, uma vez reconhecida a linha tênue entre poder de autoridade e poder autoritário, é possível entender que a liberdade, em suas mais diferentes formas de expressão, não se sobrepõe à autoridade expressa, podendo, inclusive, reafirmá-la por meio da organicidade das relações de poder democrático, constituído e pautado pela ordem e pela disciplina, indispensáveis aos processos de gestão e de organização.

Como apontado por Freire (1996), "na rebeldia da liberdade" não reside sinais de "deterioração da ordem". Muito pelo contrário, na totalidade alcançável do movimento de ordem e desordem para uma nova ordem, a expressão de 
autoridade e da liberdade se completam e se realizam e "a autoridade coerentemente democrática está convicta de que a disciplina verdadeira não existe na estagnação, no silêncio dos silenciados, mas no alvoroço dos inquietos, na dúvida que instiga, na esperança que desperta" (FREIRE, 1996, p. 36).

Com efeito, a expressão das relações democráticas tampouco é compreensível no cômputo da conduta marcada pelo silêncio como estratégia intencional daquelas(es) que, insistem na neutralidade da ação política e, desta forma, negam a exposição de ideias, de argumentos e fogem aos debates e não assumem o contraditório, Não obstante, é preciso ressaltar que a dialética se concretiza no contraditório, o que caracteriza para Freire uma forma de sectarismo. Contudo, a dialética ganha concretude a partir do contraditório, da possibilidade do conflito se efetivar como campo dialógico fértil, capaz de potencializar as relações interpessoais de forma civilizatória.

A gestão democrática de princípios democráticos, pressupõe o enfrentamento dos excessos autoritários e a superado da postura submissa e subserviente de docentes e gestoras(es), para, desta forma, fazer prevalecer o pensamento e a postura reflexiva e crítica, contextualizada, capaz de intervir para transformar

Decerto, na escola o silêncio das(os) educadoras(es), por diversas ocasiões, também tem contribuído para referendar e naturalizar os processos burocráticos e instrumentalizados de gestão educacional. Em muitos casos, de forma sutil, esses processos chegam até mesmo a induzir a padronização de práticas didáticopedagógicas, enquadradas pela vigilância ideológica. Qualquer movimento "fora da caixinha" pode significar irreverência, rebeldia e transgressão.

As escolas têm-se constituído como loci de poderes não democráticos configurados, [...], atestando a sua configuração antidemocrática ao inibir comportamentos que resultem do desrespeito às regras e às estruturas burocráticas a que se encontra constrangida. $\mathrm{Na}$ verdade, na agenda do modelo burocrático, caracterizado pela rígida hierarquia, a participação não é formalmente considerada, o próprio modelo faz-se assentar numa concepção passiva de subordinado, como se de um mero espectador se tratasse (CARVALHO, 2009, p. 443).

Não se trata de desconhecer e/ou desconsiderar a importância da racionalidade dos processos de gestão escolar em seus aspectos de organização e disciplina, desde que emancipatórios, pensados coletivamente, definidos e implementados à luz da capacidade, da competência e da autonomia dos sujeitos em operar esses processos de forma democrática, articulada com suas vivências, experiências e responsabilidades. Conforme assegura Freire (1987, p.103), “É verdade que, sem liderança, sem disciplina, sem ordem, sem decisão, sem 
objetivos, sem tarefas a cumprir e contas a prestar não há organização e, sem esta, se dilui a ação revolucionária. Nada disso, contudo, justifica o manejo das massas populares, a sua coisificação".

Nos espaços de discussão e deliberação da escola, a coisificação induzida por gestoras (es) e, em grande medida, consentida por educadoras(es) ocorre, principalmente, mediante o silêncio proposital e a negação ao debate. A conveniência da não exposição de ideias, ou mesmo a ausência de argumentações em face de processos decisórios relacionados à gestão educacional, em muitos casos, conduzidos de forma autoritária e, por vezes, velada, nega a totalidade dos processos indispensáveis à emancipação dos sujeitos.

Como bem destaca Freire (1967), a educação, enquanto ato de rebeldia, é um processo que liberta e emancipa os sujeitos, tornando-os capazes de assumir, de forma efetiva, o seu lugar de ser e estar no mundo. Contraditoriamente, a acomodação, a subserviência e a negação ao debate qualificado pavimentam o campo da gestão educacional autoritária, incapaz, portanto, de contribuir com a organicidade do processo dialógico e democrático de tomada de decisões.

Nesta perspectiva, a padronização do formato de estruturação e funcionamento da escola pública, em particular, em suas estratégias de gestão educacional, acaba por referendá-la como espaço de exclusão, que, em muitos casos, reforça privilégios e interesses de classe. Mais especificamente, quando se trata da modalidade da EJA, entendemos que a própria estrutura burocrática de organização da escola literalmente tem contribuído para negar ou mesmo dificultar o direito à educação aos sujeitos que, por diversas vezes, tiveram suas trajetórias escolares interrompidas.

Um contexto complexo que precisa ser refletido, compreendido e apreendido, a partir da leitura crítica sobre a atual conjuntura socioeconômica e política, que sob a influência direta do neoliberalismo, desvela um novo modelo de reestruturação produtiva. Uma estratégia que coaduna com o projeto perverso de revisão e redimensionamento do papel do estado, assim como do fortalecimento do mercado e aparelhamento das estruturas e superestruturas de controle e poder. É a partir dessas profundas transformações estruturais que o sistema educacional, em especial a educação pública, precisa ser repensada em sua totalidade. Afinal, que projeto de escola pública e de educação escolar defendemos para as camadas populares? A formação humana integral ou o aligeiramento do processo formativo, no âmbito da precarização e desqualificação da práxis docente?

O exercício de repensar o papel ético e político das(os) educadoras(es) das escolas públicas, na atualidade, perpassa pelo conhecimento contextualizado e crítico sobre a reestruturação do capitalismo nas contradições de seus processos e de suas múltiplas dimensões e variáveis, expressas, particularmente, no modo 
de pensar, de agir, de ser e de estar no mundo. Uma prerrogativa que não exclui o necessário e urgente compromisso de dar conta de situar a educação escolar brasileira no campo das complexidades engendradas nesses processos e dimensões permanentemente reformulados, adaptados e ressignificados em escala global.

É notadamente na esteira dos reconhecidos progressos científicos, tecnológicos e informacionais que novos e permanentes desafios exigem a posição da escola e o comprometimento de gestoras(es) e educadoras(es), no sentido de contribuírem para a necessária e urgente tomada de consciência sobre os ameaçadores sinais de obscurantismos no campo das práticas de controle, dominação e de coerção e da declarada violência simbólica (BOURDIEU, 1997) em processo.

São movimentos que também encontram lugar na escola e, por vezes, sendo eles alimentados, no âmbito da gestão educacional, acabam por comprometer toda a estrutura de organização e funcionamento do sistema de ensino. É justamente sobre esse campo de reflexão que, ao operarmos com os pressupostos da pesquisa documental e da metodologia da sistematização de experiência, objetivamos contribuir com o debate acerca da gestão educacional no contexto da crise societária e sanitária e suas graves consequências para o conjunto da comunidade escolar.

Interessa-nos destacar as soluções paliativas adotadas nas redes públicas de ensino, em especial sobre o recurso denominado ensino remoto. Trataremos exclusivamente das contradições no âmbito da gestão educacional para a implantação do ensino remoto junto às turmas dos cursos técnicos integrados do Proeja do Ifes Campus Vitória.

Não se trata de negar a importância dos recursos tecnológicos no processo de produção do conhecimento junto aos sujeitos da EJA. Paulo Freire (2000, p. 46) chama atenção para a importância da postura crítica acerca da tecnologia "como uma forma de intervenção crescentemente sofisticada no mundo, [...] a ser submetida ao crivo ético e político, [e à medida que ganha importância] a necessidade de vigilância ética sobre ela, uma ética a serviço das gentes, de sua vocação ontológica de ser mais".

Nesse contexto, em que a tecnologia, via adoção do ensino remoto, ganha importância nas decisões da gestão educacional em todos os níveis, e em que as diretrizes do mercado tendem a prevalecer sobre a das gentes (FREIRE, 2000), somos alertados a atentar para as contradições do processo da gestão educacional no âmbito do Proeja no Ifes, a partir da análise da negação dos movimentos de resistência e de resiliência em face da situação de "invisibilidade" dessas(es) educandas(os). 


\section{ENSINO REMOTO NO PROEJA: VIOLÊNCIA SIMBÓLICA E CONTRADIÇÕES NO CAMPO DA GESTÃO EDUCACIONAL}

Após a confirmação da crise sanitária, tornou-se urgente a adoção de medidas de enfrentamento, a exemplo da suspensão das aulas para reduzir os alarmantes níveis de contaminação e óbitos. Com o prolongamento da situação pandêmica, diante da pressão de grupos empresariais e governamentais para o retorno às aulas e o cumprimento do calendário acadêmico, a modalidade de educação a distância, até então proibida "como ferramenta prioritária na educação básica, torna-se a solução pragmática para o momento da crise pandêmica" (SOARES, 2020, p. 7). Essa solução imediatista desconsiderou que significativa parcela da comunidade escolar do Ifes, em especial o público da EJA, nem mesmo têm acesso à internet e muito menos, que não dominam as ferramentas tecnológicas.

Esse fato evidencia uma intervenção crescente da tecnologia, conforme alertava Freire, e que se faz objeto de reflexão nesta pesquisa quanto aos usos do ensino remoto e suas implicações para a EJA. A opção metodológica da sistematização de experiência (MACHADO, PALUDO, 2010), atrelada à pesquisa documental (CELLARD, 2008), nos possibilitou identificar, no processo, a ausência do exercício de uma gestão compartilhada, tais como as experiências iniciais que Freire nos ensina.

Assim, alterna-se a resistência de uns ao ensino remoto e a pressão de outros como possibilidade de problematizar a situação na qual encontram-se milhões de estudantes de todos os níveis e modalidades de ensino. Diante da pressão em âmbito nacional e com base nos documentos oficiais, o Ifes implantou as APNPs como medida para substituir as atividades presenciais durante a pandemia, suspensas no início do ano letivo de 2020.

Após orientações dos órgãos responsáveis, a Instituição homologou documento que objetivou regulamentar a implementação das APNPs nos cursos do Ifes e que seriam definidas pelos gestores, demais profissionais de ensino e representação estudantil de cada campus (IFES, 2020). No que diz respeito à EJA, o documento infere que:

As atividades pedagógicas não presenciais destinadas à Educação de Jovens e Adultos, quando adotadas, devem considerar, na escolha dos componentes curriculares a serem substituídos, na elaboração de metodologias e nas práticas pedagógicas, as singularidades dessa modalidade de ensino, conforme Parecer CNE/CEB no 11/2000, Resolução CNE/CEB n 01/2000 e Resolução CNE/ CEB no 3/2010 (IFES, 2020, p. 4). 
$\mathrm{Na}$ constatação da inviabilidade da adoção das APNPs, uma vez ouvido o colegiado, o gestor submeteria à Direção Geral do campus uma proposta informando a não adesão, segundo orientações dos documentos normativos. É o caso da Coordenadoria de Cursos do Proeja, que, durante o ano de 2020, não implementou tais atividades.

No Manifesto da Coordenadoria do Proeja, encaminhado à gestão do Ifes Campus Vitória, as(os) docentes argumentaram que qualquer discussão sobre os cursos do Proeja, envolvendo essa proposta de trabalho, deveria garantir a participação de toda a comunidade escolar e denunciaram que "a decisão do Comitê de Crise por adotar atividades a distância desconsidera a heterogeneidade cultural e socioeconômica dos nossos estudantes e menospreza as distinções entre os cursos, em suas particularidades de estrutura, currículo e planejamento" (MANIFESTO DA COORDENADORIA DO PROEJA, 2020, p. 8).

Nesse ínterim, as(os) estudantes do Proeja se organizaram e publicaram a Nota de Repúdio denominada: PROLUTA: A sala de aula é nosso lugar! ${ }^{1}$ Tal documento referenda a atuação organizada desse público estudantil na defesa pelo seu direito à educação e foi veiculado por meio das mídias sociais, com as(as) educandas(os) posicionado-se contrárias(os) à decisão do Ifes de manter as APNPs para todas(os) indistintamente e de forma remota.

Diante do fato das(os) estudantes não terem acesso ou facilidade para utilizar as tecnologias de informação e comunicação (TICs) e do contexto de anos de ausência da escola, as(os) docentes argumentaram que "os avanços tecnológicos não podem se dar à custa de novas formas de exclusão" (MANIFESTO DA COORDENADORIA DO PROEJA, 2020, p. 4). Quando a instituição adota uma proposta educacional e um grupo realiza e o outro não, em particular, por sua condição de classe socieconomicamente desfavorecida, transfere-se mais uma vez para as(os) discentes a responsabilidade pelo seu processo formativo e possível fracasso.

Mesmo com a suspensão das atividades letivas presenciais a partir do mês de março de 2020 e uma vez debatida e não aceita a adoção das APNPs nas turmas do Proeja, no mês de setembro de 2020 são retomadas as discussões acerca das APNPs pela Direção de Ensino do Campus Vitória. O referido documento também apresentou a possibilidade de adoção de atividades complementares de ensino - ACE.

A partir de então, novo debate foi realizado no âmbito das coordenações de cursos do Proeja sobre o que foi proposto pela gestão do Campus Vitória, expondo inúmeras contradições em relação aos encaminhamentos anteriormente 
definidos pelo conjunto das(os) docentes quando da produção e divulgação do Manifesto da Coordenadoria do Proeja, que, inclusive, referendou a mobilização de estudantes para a divulgação da nota de repúdio à adoção do ensino remoto.

Por outro lado, no âmago da proposta de adoção das APNPs, nem mesmo seus significados obscuros e comprometedores no campo das práticas pedagógicas, suas características e também seu formato de organização seletiva e excludente foram capazes de, mais uma vez, sensibilizar parte expressiva das(os) docentes do Proeja, que, movidos pela negação ao debate e pelos interesses corporativistas, nesta ocasião, aprovaram a adoção das APNPs em dois dos cinco cursos ofertados, sem a participação das(os) estudantes no debate.

$\mathrm{Na}$ esteira das calorosas discussões sobre as APNPs no Proeja, depreendemos das narrativas de educadoras(es) a ausência de argumentos justificáveis, capazes de sustentar o apoio à proposta de adesão. Para grande parte das(os) docentes, em suas manifestações durante as reuniões virtuais, prevaleceu o casuísmo, o jogo de interesses no sentido de fazer valer a burocracia do processo de gestão escolar, pautada pelas exigências de se fazer cumprir, a qualquer custo, o calendário escolar e na impossibilidade de outro calendário escolar, mesmo considerando as diferentes modalidades. Outra debate foi o sentimento de culpa, revelado nessas reuniões por diversos profissionais, pelo fato de estarem em casa, recebendo seus salários, mesmo reconhecendo que suas moradias tenham sido transformadas em ambientes de trabalho e, em muitos casos, estavam perfazendo dupla e/ou tripla jornada de atividades educativas.

No contraponto à proposta de adoção das APNPs, a Orientação Normativa divulgada pela Direção de Ensino do campus também apresentou a proposta das ACE, de cunho não obrigatório e voltadas exclusivamente para a manutenção dos vínculos com as(os) educandas (os). As ACE, embora também operacionalizada na forma de atividades remotas e, portanto, condicionada à necessidade de reconhecimento sobre os desafios dos processos de aprendizagem e de condições materiais das(os) discentes, são atividades não obrigatórias, flexíveis no sentido de considerar suas limitações relacionadas ao fator "tempo" dedicado à escola, condições de vida, de moradia, dentre outras especificidades por demais destacadas, tanto no Manifesto do Proeja, como, e, particularmente, por meio da Nota de Repúdio.

As ACE priorizam a necessidade de assegurar momentos de interação e de participação de estudantes, mesmo de forma virtual. Quanto ao disposto sobre o processo de participação das(os) estudantes em tais atividades, o documento enfatiza a condição de ser uma participação facultativa, situação que não impõe nenhuma condicionante no sentido de trancamento de matrícula, reprovação ou mesmo de obrigatoriedade quanto à participação desse público estudantil. 
Importa retomar, inspiradas em Freire, acerca da atuação das(os) professoras(os) numa escola democrática, pública e popular, em tempos de pandemia interessada na manutenção dos vínculos com as(os) discentes e que considera o saber da experiência dos estudantes a partir do qual trabalha de forma rigorosa a abordagem dos objetos de estudo (FREIRE, 2001b). A opção às ACE foi definida, inicialmente, no mês de setembro de 2020, por três dos cinco cursos do Proeja, quando ocorreram intensas discussões envolvendo educadoras(es) em suas respectivas coordenações de cursos. Em particular, cabe destacar o diferencial referente ao processo de condução das discussões no Curso Técnico Integrado em Hospedagem, que culminou com a postura equivocada de docentes que se negaram ao debate e votaram em bloco pela adesão às APNPs. Nessa mesma reunião deliberativa, outro grupo de docentes, a partir do debate qualificado e, respaldados pelo Documento Base do Proeja (BRASIL, 2007), no Manifesto do Proeja e na Nota de Repúdio das(os) estudantes contra a imposição do ensino a distância, votaram contrários à adoção das APNPs e a favor da adesão às ACE, resultando no empate entre as duas propostas apresentadas.

A situação de impasse verificada com o empate das propostas mereceu um tratamento diferenciado, conduzido pela coordenação do Curso Técnico Integrado em Hospedagem, que promoveu a mobilização e a efetiva participação qualificada das(os) estudantes nas discussões e deliberações. Após debates realizados junto ao público discente por meio dos representantes de turmas, outra reunião de coordenação foi convocada, oportunidade em que o voto das(os) discentes decidiu pela adoção das ACE no Curso de Hospedagem, com início previsto para o mês de fevereiro do ano de 2021, uma vez que as atividades letivas presenciais permaneceriam suspensas até 30 de junho do mesmo ano.

Retomando Freire, o processo vivido explicita momentos de inserção das(os) estudantes no exercício democrático de participação nas decisões sobre a opção curricular da não adesão às APNPs e a opção às ACS, exercendo a práxis educativa reflexiva, junto com um grupo de docentes eticamente comprometidas(os) com o fazer pedagógico para todas e todos.

A sutileza dos processos de gestão educacional em tempos de crise sanitária do Coronavírus não esconde a violência simbólica quando, ao impor mecanismos paliativos de funcionamento do sistema educacional, corrobora o pretendido projeto de mercadorização da educação pública brasileira 


\section{CONSIDERAÇÕES FINAIS}

Os escritos de Freire servem de alento no sentido de provocar educadoras(es) a romper com o silenciamento que reafirma a intensidade das históricas práticas antidemocráticas, assim como projeta a importância de a sociedade brasileira assumir-se como sociedade sujeito, em seu compromisso de levantar-se contra a opressão e em defesa da democracia permanentemente ameaçada.

O avanço das forças de extrema-direita, o aparelhamento do estado, o comprometimento do estado democrático de direito e o agravamento da crise sanitária têm impactado a vida do conjunto da sociedade, em especial das camadas populares, cada vez mais alijadas de seus direitos elementares assegurados pela Constituição, que aos poucos vêm sendo retirados em nome de uma ordemdesordem política e econômica perversa, também patrocinada pelas elites em conluio com o capital internacional.

$\mathrm{Na}$ atualidade, a importância do pensamento de Freire é cada vez mais recorrente, tendo em vista que o movimento de despolitização e de precarização da escola pública brasileira é parte deste perverso projeto que além de promover a total desqualificação das(os) educadores(as) transformando-as(os) em meros "despachantes" de conteúdos pasteurizados pelos recursos tecnológicos disponíveis, promove também a uberização, à medida que a implementação do ensino remoto dialoga diretamente com as estratégias definidas para o empresariamento do sistema de ensino. Nesse sentido, importa a vigilância ética e política, alertada por Freire, em relação ao papel das TICs no âmbito das escolas, considerando a tendência de sua utilização em defesa da ética do mercado em detrimento da ética do ser humano.

Transformar as moradias de educadoras(es) e discentes em locais insalubres marcados por diferentes frentes de trabalho, em parte, exprime o sentido perverso e imoral do "novo normal". De forma paulatina, vai ganhando forma o projeto de "destruição criativa" do capitalismo em suas dinâmicas e estratégias de gestão, operacionalização e controle. É nesta perspectiva que a gestão educacional, particularmente nas escolas públicas, sutilmente faz coro ao conjunto das transformações em curso no país.

Face ao exposto, às(aos) educadoras(es), alcançar o pensamento freireano é fazer valer a luta contra a "desumanização opressora" e a exploração capitalista. É, também, com certeza, permitir-se dar conta da complexidade desses processos que, por meio da gestão educacional, impõem soluções paliativas, a exemplo do ensino remoto, para, assim, pavimentar o caminho das contrarreformas do ensino médio, que interessam em demasia aos empresários da educação. 
Para a modalidade de EJA, em particular, no âmbito da estrutura dos Institutos Federais de Educação, a implementação do ensino remoto significa, com certeza, o comprometimento da qualidade de ensino a partir do intencional aligeiramento da proposta de formação. Uma estratégia que dialoga com a política de redução cada vez maior dos investimentos destinados a assegurar o direito à educação pública, laica, de qualidade e emancipatória a jovens, adultas(os) e idosas(os) brasileiras(os). O que remonta às críticas de Freire sobre o descuido da gestão pública com os investimentos na educação básica.

A experiência de resistência à adoção do ensino remoto, por meio das APNPs, nas turmas do Curso Técnico Integrado em Hospedagem, embora de forma pontual, configura-se, enquanto expressão da práxis freireana, em resposta às ameaças perversas de mercadorização da educação, assim como e, principalmente, servem de referência histórica para o conjunto das(os) trabalhadoras(es) da educação na luta em defesa da escola pública de qualidade com investimentos assegurados também para garantir o acesso aos recursos tecnológicos de forma complementar à proposta de formação em sua totalidade. Com certeza, neste contexto marcado por crises e ameaça ao direito de viver, resistir é preciso, também para assegurar o exercício da docência com dignidade.

\section{REFERÊNCIAS}

BOURDIEU, P. O poder simbólico. 10 ed. Rios de Janeiro: Bertrand Brasil, 1997.

BRASIL. Programa Nacional de Integração da Educação Profissional com a Educação Básica na modalidade de Educação de Jovens e Adultos - PROEJA. Documento Base. Brasilia: Secretaria de Educação Profissional e Tecnológica, 2007. Disponível em: http://portal.mec.gov.br/setec/arquivos/pdf2/proeja_ medio.pdf. Acesso em: 30 dez. 2019.

CAETANO, Camila Gomes Arelaro; ARELARO, Lisete Regina Gomes. Políticas atuais, transformações sociais e a perseguição a Paulo Freire. Revista Estudos Culturais, n. 5, 2020. Disponível em: https://www.revistas.usp.br/revistaec/ article/view/170628. Acesso em: 11 mar. 2021. 
CARVALHO, Maria João. Paulo Freire: a construção da escola democrática a partir da decisão. Revista Brasileira de Politica e Administração da Educação. GOIÁS: RBPAE - v.25, n.3, p. 441-454, set./dez. 2009. Disponível em: https:/ / www.seer.ufrgs.br/rbpae/article/viewFile/19659/11458. Acesso em: 11 mar. 2021.

CELLARD, A. A análise documental. In: POUPART, J. et al. A pesquisa qualitativa: enfo-ques epistemológicos e metodológicos. Petrópolis: Vozes, 2008. p. 295-316.

DIAS, Rodolfo Palazzo. A desdemocratização brasileira. Disponível em: https://aterraeredonda.com.br/a-desdemocratizacao-brasileira/. Acesso em: 10 abr. 2021.

FREIRE, Paulo. Educação como prática da liberdade. Rio de Janeiro: Editora Paz e Terra Ltda, 1967.

FREIRE, Paulo. Pedagogia do Oprimido. Rio de Janeiro: Paz e Terra, 1987.

FREIRE, Paulo. A educação na cidade . São Paulo: Cortez Editora, 1991.

FREIRE, Paulo. Pedagogia da Autonomia: saberes necessários à prática educativa. 25. ed. São Paulo: Paz e Terra, 1996.

FREIRE, Paulo. Educação e atualidade brasileira. São Paulo: Cortez Editora, Instituto Paulo Freire, 2001a.

FREIRE, Paulo. Política e Educação: ensaios. - 5a ed. - São Paulo, Cortez, 2001b. (Coleção Questões de Nossa Época; v.23)

FREIRE, Paulo. Cartas a Cristina: Reflexões sobre minha vida e minha práxis. Organização e notas de Ana Maria Araújo Freire. Rio de Janeiro: paz e Terra, 2013.

INSTITUTO BRASILEIRO DE GEOGRAFIA E ESTATÍSTICA. Pesquisa Nacional por Amostra de Domicílios Contínua (PNAD): Educação 2019. Rio de Janeiro, RJ. 2020. Disponível em: https://biblioteca.ibge.gov.br/visualizacao/ livros/liv101736_informativo.pdf. Acesso em: 17 ago. 2020. 
INSTITUTO FEDERAL DE EDUCAÇÃO, CIÊNCIA E TECNOLOGIA DO ESPÍRITO SANTO. Resolução do Conselho Superior $\mathbf{n}^{\mathbf{0}} 01$ de 07 de maio de 2020. Regulamenta e normatiza a implementação das atividades pedagógicas não presenciais em cursos presenciais, técnicos e de graduação do Ifes, em função da situação de excepcionalidade da pandemia do novo Coronavírus (Covid19). Vitória, ES. 2020. Disponível em https://ifes.edu.br/images/ stories /Resolu\%C3\%A7\%C3\%A3o_CS_1_2020_Atividades_N\%C3\%A3o_ Presenciais_-_documento_submetido_a_revis\%C3\%A3o_textual.pdf. Acesso em: 10 nov. 2020.

MACHADO, R. de C.; PALUDO, C. A sistematização como um dos métodos da Educação Popular. In: Anais Anped Sul, 2010. Disponível em: <http:// www.portalanpedsul.com.br/admin/uploads/2010/educacao_e_movimentos_ so ciais/trabalho/02_10_39_a_sistematizacao_como_um_dos_metodos_da_ educacao_popular.pdf>. Acesso em: 25 jun. 2020.

Manifesto da Coordenadoria do PROEJA contra a implementação da Educação à Distância 2020. Disponível em: https://www.sinasefeifes.org.br/ wp-content/uploads/2020/04/Manisfesto-Proeja_EaD.pdf. Acesso em: 27 set. 2020.

MIGUEL, Luís Felipe. O colapso da democracia no Brasil: da constituição ao golpe de 2016. 1. ed. São Paulo: Fundação Rosa Luxemburgo, Expressão Popular, 2019. (Coleção Emergências).

PROLUTA EJAIFES. Nota de Repúdio - PROLUTA: A sala de aula é nosso lugar! Vitória, 12 abr. 2020. Instagram: @proluta.ejaifes. Disponível em: https:/ / www.instagram.com/p/B-5zjJDJswU/. Acesso em: 25 set. 2020.

ROSAS, Paulo. Recife: cultura e participação (1950-64).In: FREIRE, Paulo. Educação e atualidade brasileira. São Paulo: Cortez Editora, Instituto Paulo Freire, 2001. XLIX -LXXV.

SOARES, Sávia Bona V. O Coronavírus e a modernidade conservadora da Educação In: SOARES, Sávia Bona V. et al. (org.). Coronavírus, educação e luta de classes no Brasil. Editora terra Sem Amos: Brasil, 2020. p. 5-14. 


\section{Edna Castro de Oliveira}

Possui graduação em Pedagogia pela Universidade Federal do Espírito Santo (UFES - 1974), mestrado em Educação pela UFES em 1988, doutorado em Educação Brasileira pela Universidade Federal Fluminense (2005) e pós doutorado em Educação pela Universidade Federal do Espírito Santo (2017). Atualmente é professora associada da UFES, integra a linha de pesquisa Educação, Formação Humana e Políticas Públicas do PPGE/CE/UFES. Compõe a coordenação do Núcleo de Educação de Jovens e Adultos do Centro de Educação da UFES. Tem se dedicado à pesquisa na formação de educadores de jovens e adultos, interface com as seguintes áreas: alfabetização, educação do campo, educação profissional, políticas públicas e movimentos sociais. E-mail: oliveiraedna@yahoo.com.br.

\section{Aldo Rezende}

Pós-doutorando na área de educação, UFES; Doutor em Planejamento Urbano e Regional-UFRJ; Mestre em Geografia-UFES; Mestre na área de Ciências Sociais: (turismo e hospitalidade) Universidade Anhembi Morumbi-SP; Especialista em Planejamento Educacional-Universo-RJ; Graduado em Geografia e História PUC/MG e Faculdade de Ciências Humanas de Vitória. Professor do Programa de Mestrado em Educação Profissional e Tecnológica - ProfEPT; Professor e coordenador de curso técnico integrado, IFES-Campus Vitória; Coordenador do programa de extensão do Proeja, campus Vitória-ES; Pesquisador na área de turismo, subárea de geografia urbana, regional e cultural; Consultor e assessor técnico em programas e projetos urbanos e regionais. E-mail: aldorezendebh@ gmail.com

\section{Maria José de Resende Ferreira}

Graduada em História pela Universidade Federal do Ceará (1990). Especialista em História do Brasil (PUC/MG) e em Educação Profissional Técnica Integrada ao Ensino Médio na Modalidade de Educação de Jovens e Adultos (CEFETES). Mestre em Educação Profissional pelo Instituto Superior Pedagógico para a Educação Técnica e Profissional Hector A. Pineda Zaldivar . Havana/ Cuba, revalidado pela UFG (2003). Doutora em Educação pelo Programa de Pósgraduação em Educação da Universidade Federal do Espírito Santo (PPGE/ CE/UFES) (2017) na linha de pesquisa Diversidade e Práticas Educacionais Inclusivas. É professora efetiva do Instituto Federal de Educação Tecnológica do Espírito Santo. Atua na formação de professores nos cursos de Licenciatura, da Pós-graduação, da Educação a Distância e da modalidade de Educação de Jovens e Adultos. Integra o grupo de Pesquisa Observatório da Educação (Obeduc UFES/UNB/UFG); o Grupo de Pesquisa em Educação Profissional (GEPEP/ Ifes) e o Grupo Interinstitucional de Estudos em Educação e Inovação (SETEC/ BRASIL/CANADA) em que se dedica a pesquisas acerca do sujeitos da EJA e do Proeja, relações de gênero e étnico-raciais, educação e trabalho, diversidade e formação de professores. E-mail: majoresende@yahoo.com.br 


\section{Patrícia Helmer Falcão}

Patrícia Helmer Falcão é Mestranda do Programa de Mestrado Profissional em Educação Profissional e Tecnológica - ProfEPT e licenciada em Pedagogia pela Faculdade São Geraldo. Atua como Técnica em Assuntos Educacionais na Universidade Federal do Espírito Santo, na Pró-Reitoria de Graduação, Vitória, ES, Brasil. E-mail: triciahelmer@hotmail.com 